\title{
Aircraft Wake Vortex Core Size Measurements
}

D. P. Delisi, G. C. Greene, R. E. Robins, D. C. Vicroy, F. Y. Wang

21st AIAA Applied Aerodynamics Conference Orlando, FL June $23^{\text {rd }}-26^{\text {th }}, 2003$ 
$21^{\text {st }}$ AIAA Applied Aerodynamics Conference, Orlando, FL, June $23^{\text {rd }}-26^{\text {th }}, 2003$

\title{
AIRCRAFT WAKE VORTEX CORE SIZE MEASUREMENTS
}

\author{
Donald P. Delisi ${ }^{1 *}$ \\ George C. Greene ${ }^{2 \dagger}$, \\ Robert E. Robins ${ }^{1 \ddagger}$, \\ Dan C. Vicroy ${ }^{3 \S}$, and \\ Frank Y. Wang ${ }^{4 \pi}$
}

\author{
NorthWest Research Associates, Inc., Bellevue, WA \\ FAA R\&D Field Office, NASA Langley Research Center, Hampton, VA \\ Vehicle Dynamics Branch, NASA Langley Research Center, Hampton, VA \\ Volpe National Transportation Systems Center, Cambridge, MA
}

\begin{abstract}
We have examined data from three aircraft field tests designed, in part, to measure the size of the vortex cores generated by the aircraft. The field tests were performed between 1990 and 1997 at Idaho Falls, ID, Wallops Island, VA, and John F. Kennedy International Airport (JFK) in NY. At Idaho Falls, an instrumented 200-foot tower was used to measure velocities in the wakes of Boeing 727, 757 and 767 aircraft flown upwind of the tower. In the Wallops Island test, velocities and smoke trails behind a Lockheed-Martin C-130 aircraft were measured by an instrumented North-American Rockwell OV-10 aircraft flown behind the C-130. For the JFK tests, the vortex wakes of landing aircraft were measured by a Continuous Wave lidar operated by MIT/Lincoln Laboratories. The results from all three field tests are quite consistent, and suggest that the size of the velocity cores in trailing vortices behind an aircraft is on the order of one percent of the wingspan of the aircraft, where core size is defined as the radial distance from the vortex center to the point of maximum tangential velocity. We note that numerical simulations of trailing vortex evolution typically use velocity vortex core sizes in the range from five to twelve percent of the wingspan of an aircraft. Thus, the values of velocity core size used in numerical models are significantly larger than the full-scale values reported here. We also show that a typical size of smoke trails, where smoke is used to visualize the vortices behind an aircraft, is approximately twice the size of the velocity core.
\end{abstract}

\footnotetext{
${ }^{*}$ Senior Member AIAA, Senior Research Scientist

Associate Fellow AIAA, Manager

* Senior Member AIAA, Research Scientist

$\S$ Associate Fellow AIAA, Senior Research Engineer

${ }^{\text {II }}$ Senior Member AIAA, Aerospace Engineer
} 


\section{INTRODUCTION}

Aircraft wake vortices from a lead aircraft are a potential hazard to a following aircraft. There have been many studies of wake vortex evolution in recent years. However, one of the characteristics of aircraft wake vortices that has been difficult to measure is their core size, defined here as the distance from the center of the vortex to the radial position of maximum tangential velocity. Because the Reynolds numbers of aircraft wake vortices are large, it is important to measure core sizes to confirm that numerical simulations are correctly predicting aircraft wake vortex evolution. In most numerical simulation studies, the vortex core ranges in size from $5 \%$ to $12 \%$ of the wingspan of the generating aircraft ${ }^{1-5}$.

We have recently analyzed data from three field programs to estimate aircraft wake vortex core size. These field programs were performed between 1990 and 1997, at Idaho Falls, Idaho, Wallops Island in Virginia, and at John F. Kennedy International Airport (JFK) in New York.

This paper will discuss the core size measurements from these three field programs. Section 2 discusses the Wallops Island test, Section 3 presents results from the Idaho Falls test, and Section 4 discusses the JFK test. A summary and conclusions are given in Section 5.

\section{RESULTS FROM THE WALLOPS ISLAND TEST}

In 1995 and 1997, NASA used an instrumented North-American Rockwell OV-10 aircraft to probe the wake of a Lockheed-Martin C-130 aircraft ${ }^{6}$. The C130 aircraft is a four-engine turboprop with a geometric wingspan of 132 feet 7 inches. The weight of the aircraft during the test period ranged from 95,000 to 113,000 pounds.

Probes were mounted on three booms on the OV10 , located on each wingtip and on the nose. The probes measured the velocities of the airflow encountered by the OV-10. These measurements were used to define the velocity structure inside the vortex wake of the C-130 and to characterize the ambient atmosphere around the wake vortex measurements.

For the data shown here (Flight 705, Run 37), the C-130 flew in a clean configuration at a constant speed $(140 \mathrm{kt})$ and heading at a constant flight altitude of $7,000 \mathrm{ft}$ on a track perpendicular to the ambient wind (25 kt). Smoke canisters on the wing tips of the C-130 marked the vortices, allowing the OV-10 to locate and fly through the vortex wake. Figure 1 shows a picture taken during this run from a video camera mounted on the left tail of the OV-10. The picture shows the left wing of the OV-10 at the bottom of the picture and the front part of the cockpit on the right side of the picture. The wake vortices, visualized by the smoke from the C130, are seen in the center portion of the picture (port vortex) and snaking off the right side of the picture (starboard vortex).

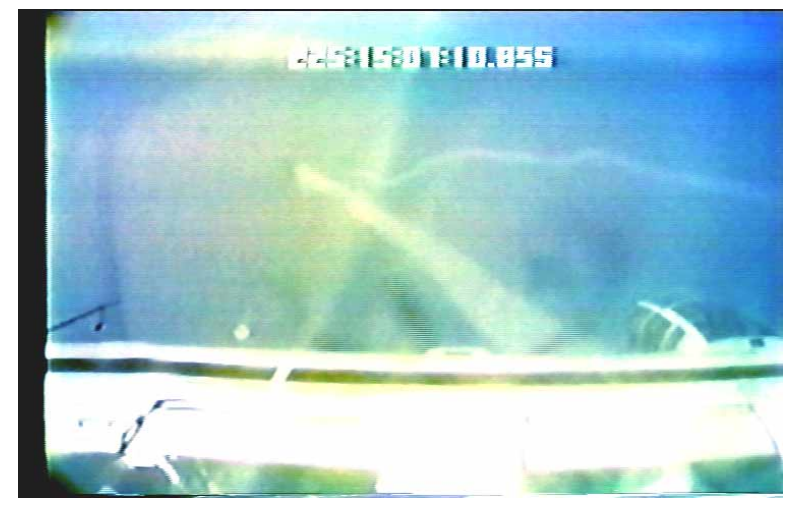

Figure 1. Single frame picture from the video camera on the tail of the $\mathrm{OV}-10$ as it crosses the smoke trail left by the $\mathrm{C}-130$. The picture was taken 5.7 miles behind the $\mathrm{C}-\mathbf{1 3 0}$

The OV-10 started its data measurements nearly broadside to the $\mathrm{C}-130$ and made a series of measurements into the wake of the C-130 at gradually increasing distances behind the C-130. To perform a wake crossing, the OV-10 would enter into the wake of the $\mathrm{C}-130$ from one side. The pilot of the OV-10 would attempt to pass through the smoke trail, indicating one vortex from the $\mathrm{C}-130$, and then through the other smoke trail. The procedure would then be repeated from the other side of the wake. For this run, the separations between the C-130 and the OV-10, measured using GPS, ranged from 0.3 to $6.5 \mathrm{~nm}$.

\subsection{Estimates of Vortex Core Size Using Velocity $\underline{\text { Measurements }}$}

For each wake crossing, we computed the tangential velocities measured by the velocity probes on all three booms. As shown in ref. 6, the velocity probes on the left, nose, and right booms would measure similar, but not identical, velocity traces for a given pass through the wake. Also, although it was attempted, the OV-10 rarely passed through the cores of both vortices on any given wake crossing, as the OV-10 would be thrown off its intended trajectory by the motions induced by passing through the first vortex. Consequently, for each wake crossing, we chose the "best" tangential velocity trace for analysis. The "best" 
trace was chosen using two criteria. First, the velocity trace had to show two peaks, with significant reduced velocities between the peaks. We call this type of profile an " $\mathrm{M}$ " profile. If the tangential velocity trace showed only a single peak, the probe was assumed to pass on a trajectory outside the vortex core. If there were significant reduced velocities between two peaks, and, hence, an " $M$ " profile, it was assumed that the probe passed through the maximum tangential velocities and into the slower velocities in the vortex core. Second, if there were two similar traces, the trace with the smaller velocities between the velocity peaks was chosen, as it was assumed that probe came closer to the vortex center. If no tangential velocity trace showed two peaks with reduced velocities between the peaks, no trace was analyzed for that crossing. If two traces showed similar traces, both traces were analyzed.

An example of an acceptable tangential velocity trace is shown in Figure 2. This figure shows the tangential velocity as a function of radial distance from the port vortex using velocity measurements from the left boom. The zero radial distance is chosen as the location of the minimum tangential velocity inside the vortex core. Note the two velocity maxima, with peak velocities of 84 and $113 \mathrm{ft} / \mathrm{sec}$, with markedly smaller velocities between the maxima.

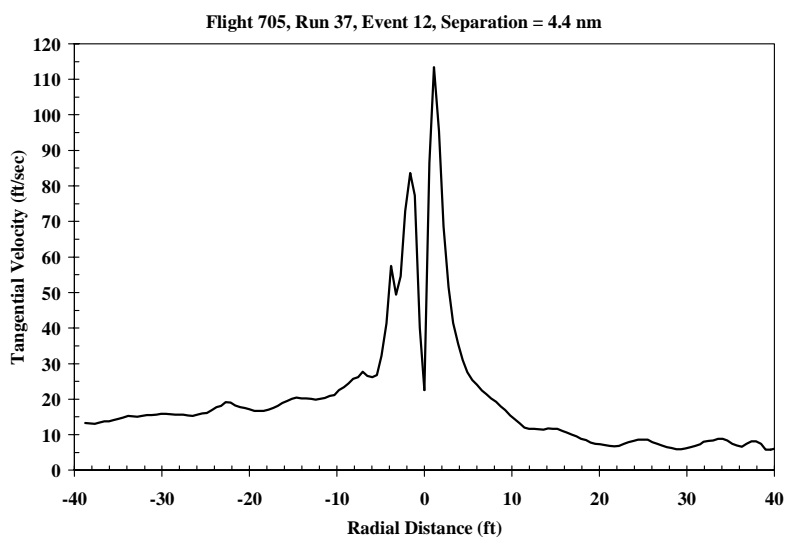

Figure 2. Tangential velocity trace showing a characteristic "M" profile from the velocity probe on the left boom of the OV-10 as it passes through the port vortex generated by the $\mathrm{C}-130$. The separation between the $\mathrm{OV}-10$ and the $\mathrm{C}-130$ was $4.4 \mathrm{~nm}$.

We are interested in estimating the distance between the velocity peaks in Figure 2 . Based on the data in Figure 2, the core radii are less than $2 \mathrm{ft}$. However, because the probe does not pass through the exact center of the vortex, we will underestimate the vortex radius if the velocity minimum between the velocity peaks is non-zero. To correct this underestimate of core radius, we calculated new vortex core radii based on the Hallock-Burnham vortex model ${ }^{7}$ and the maximum and minimum observed velocities around the vortex cores. The results of these calculations are shown in Figure 3. This figure shows tangential velocity profiles vs. corrected radius for the vortex core for separations from $0.3 \mathrm{~nm}$ to $6.0 \mathrm{~nm}$ behind the $\mathrm{C}-130$. In all the cases shown, the correction to the core radius was less than $0.25 \mathrm{ft}$, and the median correction was $0.02 \mathrm{ft}$. For the profiles in Figure 3, the core radius varies from $0.4 \mathrm{ft}$ to $1.8 \mathrm{ft}$.

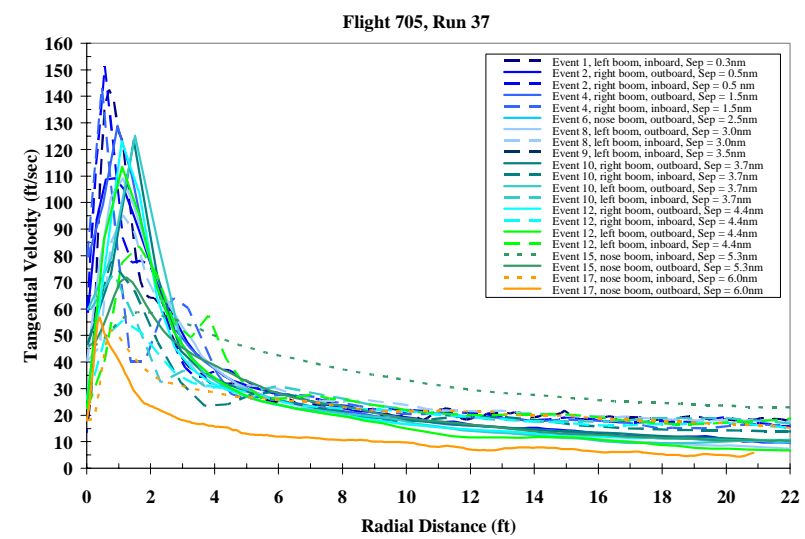

Figure 3. Velocity profiles from Flight 705, Run 37. Only "M" profiles are plotted; consequently, the probe went through the core of the vortex. The profiles have been corrected for the probes not passing through the very center of the core. Inboard and outboard portions of the profile have been overlapped to more easily show the radius of the maximum tangential velocities. Separations between the $\mathrm{OV}-10$ and the $\mathrm{C}-130$ range from $0.3 \mathrm{~nm}$ to $6.0 \mathrm{~nm}$.

\subsection{Estimates of Vortex Core Size Using Smoke}

The videos taken from the tail of the OV-10 during the vortex encounters, such as shown in Figure 1 , were analyzed to determine the diameters of the smoke trails from the C-130. This analysis was undertaken because many wake visualizations using smoke or condensation have been reported ${ }^{8,9}$, but it is not known how these measurements relate to the size of the vortex cores based on velocity measurements.

To estimate the vortex core size using smoke, we performed single-frame analyses of the videos of the vortex encounters. For each vortex crossing, we demanded that the smoke be close to the wing, with good visibility and good contrast between the smoke and the surrounding environment. To estimate core size, we chose a reference point on the wing and counted the number of video frames it took for the 
smoke trail to pass by that point. For many crossings, we repeated the estimate using different reference points. Then, knowing the lateral position of the OV10, including the effect of the ambient wind, we calculated the lateral velocity of the OV-10 at the time of crossing the smoke trail. With this information and the video frame rate of 30 frames/sec, we could estimate the diameter, and, hence, the radius, of the smoke trail.

\subsection{Results for Flight 705 , Run 37}

Figure 4 shows the estimates of the velocity vortex diameters (triangles) and the smoke vortex diameters (squares) as a function of separation distance. For the velocity measurements, we obtain an estimate of the vortex core radius from both the inboard and the outboard side of the vortex. For the minimum diameter of the velocity core size, we took twice the value of the smaller of the two radius estimates, and for the maximum diameter of the velocity core size, we took twice the larger value of the two estimates. Figure 4 shows that the differences between minimum and maximum estimates are small. The heavy, solid line is the least squares fit through the solid triangles, and the heavy, dashed line is the fit through the open triangles. The thin, solid line is the least squares fit through the solid squares, and the thin, dashed line is the fit through the open squares.

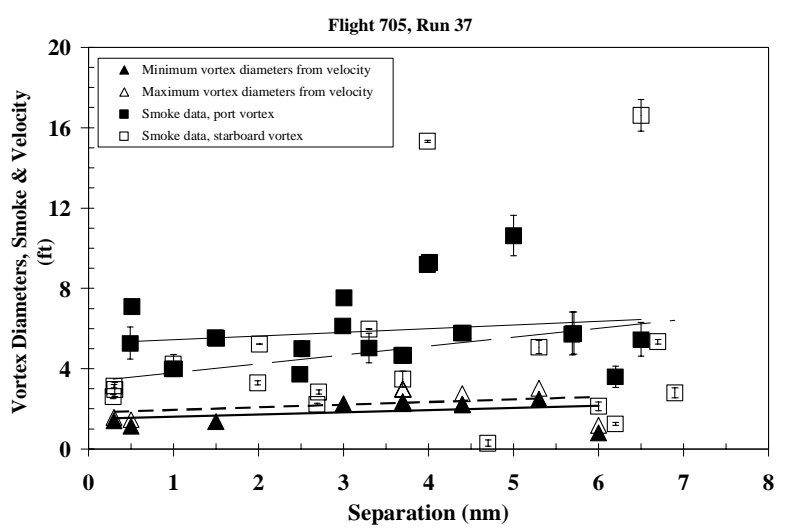

Figure 4. Vortex core diameter results from Flight 705, Run 37, in units of feet, as a function of separation distance in nautical miles. The minimum vortex diameters from the velocity measurements are shown as the solid triangles. The maximum vortex diameters from the velocity measurements are shown as the open triangles. The diameters of the port vortex from the smoke measurements are shown as the solid squares. The diameters of the starboard vortex from the smoke measurements are shown as the open squares. The heavy, solid line is the least squares fit through the solid triangles; the heavy, dashed line is the fit through the open triangles; the thin, solid line is the least squares fit through the solid squares; and the thin, dashed line is the fit through the open squares. Estimates of the errors in determining the smoke radii are shown by the error bars.

Figure 5 shows the data in Figure 4 as vortex core radius in nondimensional form. Here, the vortex radius is normalized by the wingspan of the $\mathrm{C}-130$, and $\mathrm{T}$ is nondimensional time, defined as $\mathrm{T}=\mathrm{V}_{\mathrm{o}} \mathrm{t} / \mathrm{b}_{\mathrm{o}}$, where $\mathrm{V}_{\mathrm{o}}$ is the initial descent rate of the vortices from the C-130, estimated from a plot of vertical position of the vortex wake vs. time behind the C-130 as $2.62 \mathrm{ft} / \mathrm{sec}$, $\mathrm{t}$ is time behind the $\mathrm{C}-130$, assuming a known separation and a constant airspeed of the C-130 of $140 \mathrm{kt}$, and $b_{o}$ is $\pi / 4$ times the wingspan of the C-130. For the C-130 measurements, one unit of $\mathrm{T}$ corresponds to a distance of approximately 1.5 nautical miles behind the aircraft.

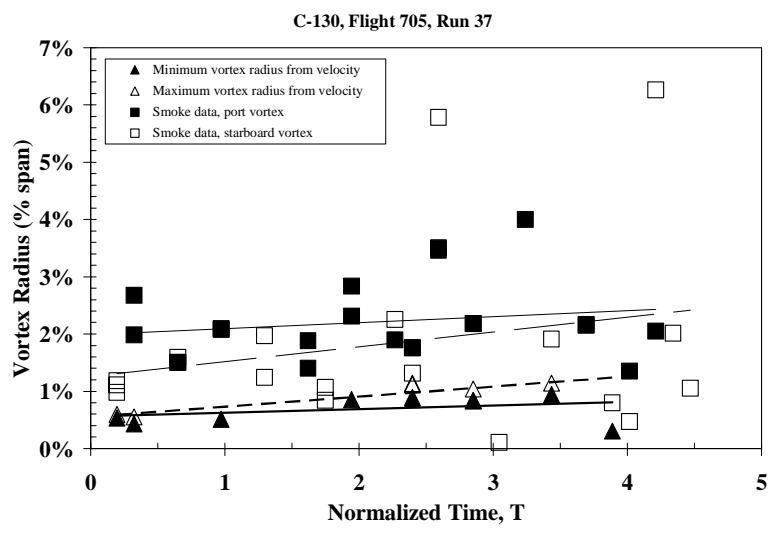

Figure 5. Similar to Figure 4 only vortex core radius in nondimensional units.

The least squares fits in Figure 5 indicate that the velocity vortex core radius estimates behind the C-130 are typically 1 percent of wingspan or less and are nearly constant with $\mathrm{T}$. The least square fits to the smoke data indicate that the estimates of the radius of the vortex smoke tubes are typically 2 percent of the wingspan of the C-130 and are also nearly constant with $\mathrm{T}$. We expect that the radius of the smoke tubes might be larger than the radius of the velocity cores, since the smoke is not exclusively located inside the region bounded by the maximum tangential velocity and may leak out of the core into the vortex cell surrounding the core. Indeed, the videos showed that the edges of the smoke tubes often were not sharp, but were diffuse, making it difficult to obtain accurate estimates of the diameters of the smoke tubes. 


\section{RESULTS FROM THE 1990 IDAHO FALLS FIELD TEST}

In 1990, the FAA conducted tests to investigate the vortex wakes of Boeing 727, 757, and 767 aircraft. The tests were conducted at the NOAA vortex test facility near Idaho Falls, Idaho ${ }^{10}$. The tests were conducted using the tower flyby technique, where an aircraft follows a predetermined path upwind and approximately 90 degrees to the ambient wind. This crosswind then carries the wake vortices generated by the aircraft over the sensors, which are located at fixed positions on the ground. One of the measurement systems used in this test was a 200-foot tower containing hot-film anemometers. These anemometers were located every 2 feet vertically on the tower, starting at $10 \mathrm{ft}$ above the ground. A total of 198 sensors were placed on the tower, 99 on one side of the tower, and 99 on the opposite side, for ambient wind coming from the opposite direction. Each anemometer measured the tangential component of the vortexinduced velocity at its vertical height. Processed data were made available at $100 \mathrm{~Hz}$. Most of the available data are in 5-second increments, roughly centered on the passage of either the downwind or the upwind vortex through the tower. For a few, selected runs, 5minute data are also available.

Figure 6a shows the time series of tangential velocity from 5 hot film probes centered on $162 \mathrm{ft}$, when the downwind vortex from a 757 passed through the tower. For this run (designated Run 9), the 757 was in a landing configuration at a speed of $135 \mathrm{kt}$, on a zero-degree glide slope, and the flaps were extended (flaps 30). The age of the vortex shown is $14 \mathrm{sec}(\mathrm{T}=$ 1.0). The velocity scale is $50 \mathrm{ft} / \mathrm{sec}$, as shown on the bottom right scale. Note that the signal at a height of $162 \mathrm{ft}$ shows a slight M-profile, and that the peak velocities are nearly twice those of the next closest sensors. Figure $6 \mathrm{~b}$ shows similar time series for 757 Run 15. For this run, the 757 was in a clean configuration (no flaps or landing gear extended), traveling at a speed of $250 \mathrm{kt}$ on a zero-degree glide slope. The age of the vortex shown is $34 \sec (\mathrm{T}=1.2)$. The middle time series in this plot, at a height of $122 \mathrm{ft}$, also shows an M-profile, which is absent from the other probes on either side. Note, too, that the peak velocities of $122 \mathrm{ft}$ are nearly twice those of the surrounding sensors.

Figure 6 shows that the 757 cores are small compared to the spacing of $2 \mathrm{ft}$ of adjacent sensors. (The sensor at $164 \mathrm{ft}$ in Figure 6a cannot be in the core since the maximum tangential velocity it recorded was half that of the sensor at $162 \mathrm{ft}$.)

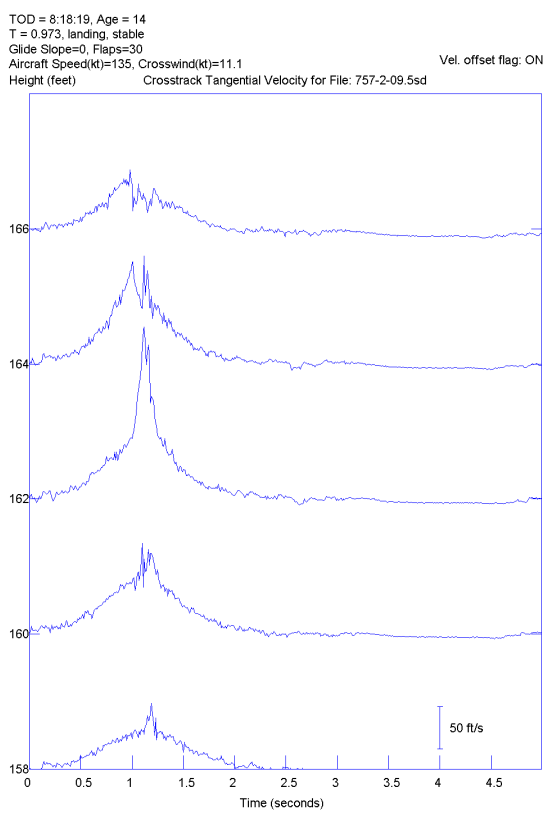

Figure 6a. Time series data from hot film probes on the 200 -ft tower from the Idaho Falls test. The plot shows 5 seconds of data from the probes at $158 \mathrm{ft}$ (bottom) to $166 \mathrm{ft}$ (top). The vortex was centered on the probe at $162 \mathrm{ft}$. The vortex was generated by a 757 in a landing configuration (Run 9). The wake age is $14 \mathrm{sec}$.

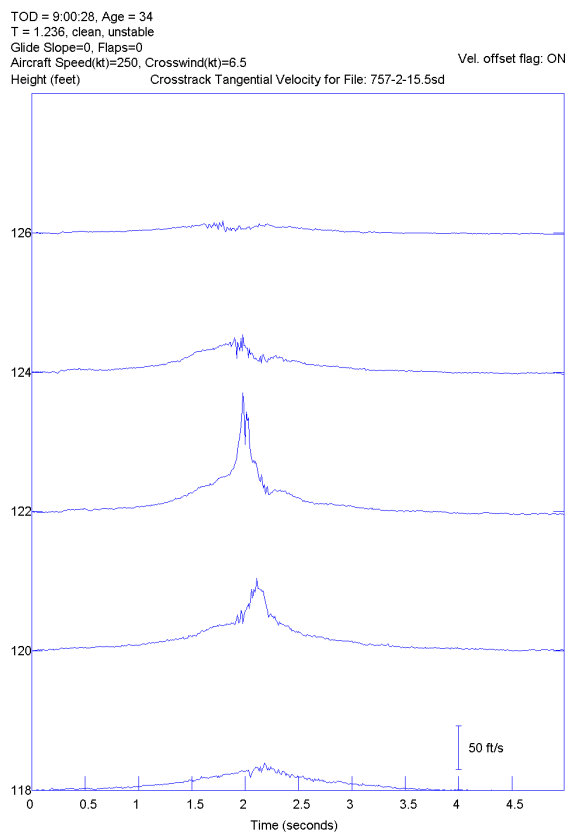

Figure 6b. Similar to Figure 6a, only for the 757 in a clean configuration. The plot shows data from probes at $118 \mathrm{ft}$ (bottom) to $126 \mathrm{ft}$ (top). The wake age is 34 sec. 
We hypothesize that, as the vortex moves past the tower, the tower will initially impede the motion of the vortex through it, and the tower will act as an obstacle. Then, once the vortex on the sides of the tower have migrated past the tower, the vortex passing through the tower will "snap" through the tower at a migration velocity that is larger than the ambient wind. To confirm this hypothesis, we have calculated the circulation of the vortex for 757 Run 9. To obtain the circulation as a function of radial distance, we used an ambient wind of $8.5 \mathrm{ft} / \mathrm{sec}$, determined by using many wind speeds and minimizing the variance of the average circulation between 3 and $10 \mathrm{ft}$. The circulation plot using this value of the ambient wind is shown in Figure 7 for the downwind half of the vortex shown in Figure 6a. For the radial distance between 3 and $10 \mathrm{ft}$, the average circulation is $993 \mathrm{ft}^{2} / \mathrm{sec}$, and this value is shown by the dashed line in Figure 7.

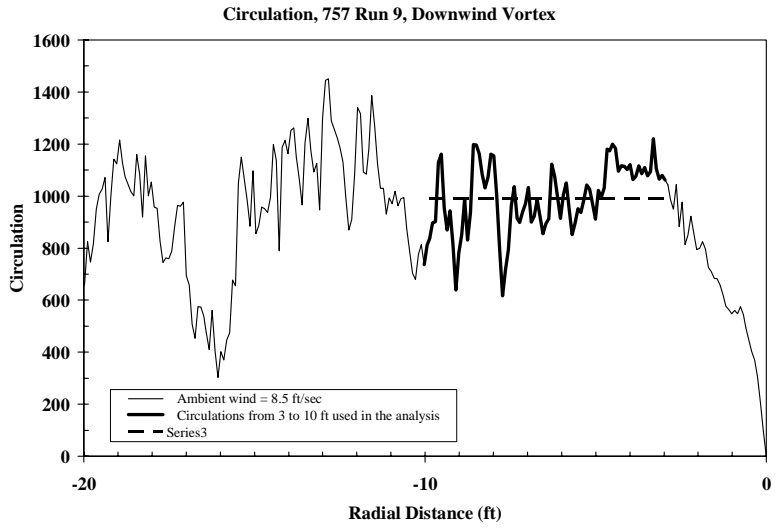

Figure 7. Circulation for the downwind portion of the vortex shown in Figure 6a at $162 \mathrm{ft}$. An ambient wind of $8.5 \mathrm{ft} / \mathrm{sec}$ was used to convert from time to radial distance. The portion from 3 to $10 \mathrm{ft}$ is shown as the heavy, solid line. The average circulation between 3 and $10 \mathrm{ft}$ is $993 \mathrm{ft}^{2} / \mathrm{sec}$, and is shown by the dashed line.

Using the measured weight of the aircraft and other measured parameters, we estimate that the initial circulation of the 757 for Run 9 was $4,176 \mathrm{ft}^{2} / \mathrm{sec}$. Using Fig. 8 in ref 11 , we estimate that the average decay of vortices out of ground effect is 1-(T/12). Thus, at $\mathrm{T}=1$, the circulation of the 757 in Run 9 should be around $3,830 \mathrm{ft}^{2} / \mathrm{sec}$, a far larger number than the value of $993 \mathrm{ft}^{2} / \mathrm{sec}$ calculated using the ambient wind.

Figure 8 shows the data in Figure 7 with values of snap velocity ranging from 10 to $50 \mathrm{ft} / \mathrm{sec}$. Note that this snap velocity is in addition to the $8.5 \mathrm{ft} / \mathrm{sec}$ ambient wind. The solid lines in Figure 8 indicate the average circulation in the region bounded by 3 to $10 \mathrm{ft}$ with only an ambient wind of $8.5 \mathrm{ft} / \mathrm{sec}$. (Note that the extent of this region grows with increasing snap velocity.) The thick black line in Figure 8 is for a snap velocity of 32.6 $\mathrm{ft} / \mathrm{sec}$. Using this value of the velocity gives an average circulation outside of the core region of $3,830 \mathrm{ft}^{2} / \mathrm{sec}$.

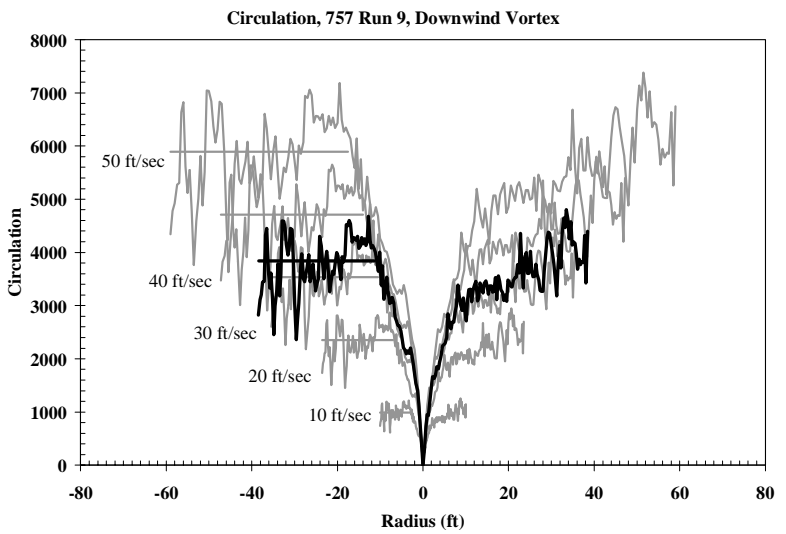

Figure 8. Circulation as a function of radius for an ambient wind of $8.5 \mathrm{ft} / \mathrm{sec}$ and snap velocities ranging from 10 to $50 \mathrm{ft} / \mathrm{sec}$. The solid black lines are for a snap velocity of $32.6 \mathrm{ft} / \mathrm{sec}$, which gives an average circulation outside of the core region of $3,830 \mathrm{ft}^{2} /$ sec.

Note in Figure 6 that the hot film did not pass through the center of the core, as evidenced by the fact that the velocity between the peaks did not drop to zero. If we use the difference between the peak velocities, we will underestimate the core radius. As above, we calculated new vortex core radii based on the HallockBurnham vortex model ${ }^{7}$.

For Run 9, the new, corrected radii (for the outboard and the inboard portions of the vortex shown in Figure 6a) are 0.75 and $0.81 \mathrm{ft}$. Using a 757 wingspan of $124.8 \mathrm{ft}$, this gives a core radius of 0.60 and 0.65 percent of wingspan. These values are consistent with the velocity core sizes shown on Figure 5 for the C-130.

\section{RESULTS FROM THE 1997 JFK TEST}

The third field program we analyzed took place at JFK airport in November 1996 and May-June of 1997. This field program was designated JFK2. The test incorporated many sensors to measure the vortex wakes of landing aircraft, among which was a Continuous Wave (CW) lidar operated by MIT/Lincoln Laboratories. $^{12,13}$ On one day in particular (May 31, 1997), the lidar measurements resulted in smaller core sizes than had been previously observed. It was speculated at the time that condensation in the wake 
vortices increased the signal-to-noise ratio for the lidar, resulting in higher velocities being observed closer to the vortex center.

Figures 9 and 10 show velocity profiles for 2 aircraft landing during this day, a landing by a B-757 (Figure 9) and a landing by an MD11 (Figure 10), which landed 22 min after the 757 .

For the B-757, the median vortex core radius for the data shown in Figure 9 is $0.5 \mathrm{~m}(1.64 \mathrm{ft})$. With a wingspan of $124.5 \mathrm{ft}$, this corresponds to a core radius of 1.3 percent of wingspan. For the MD11, the median vortex core radius for the data shown in Figure 10 is $0.7 \mathrm{~m}(2.3 \mathrm{ft})$. With a wingspan of $169.5 \mathrm{ft}$, this corresponds to a core radius of 1.4 percent of wingspan.

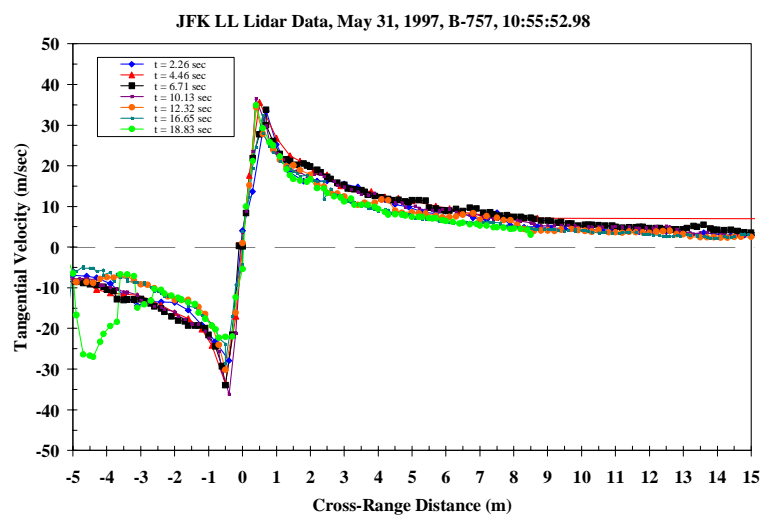

Figure 9. Velocity profiles measured behind a B-757 aircraft by the MIT/Lincoln Labs lidar at JFK airport on May 31, 1997. The profiles range from 2.2 to 18.3 sec behind the B-757.

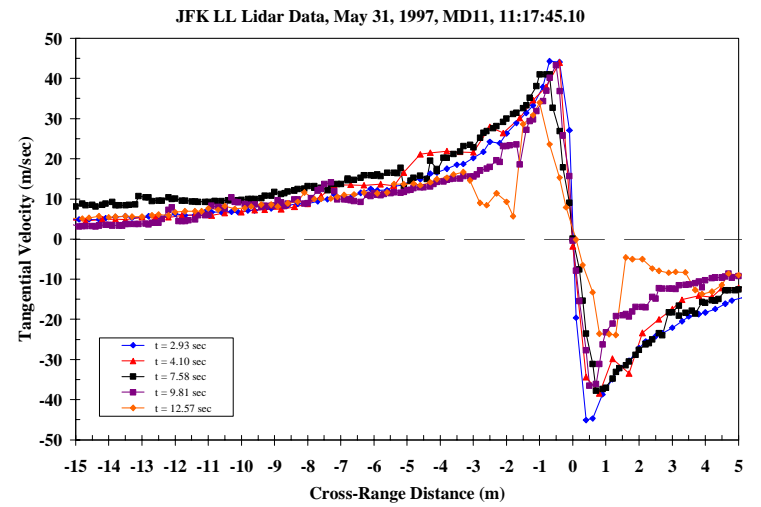

Figure 10. Velocity profiles measured behind an MD11 aircraft by the MIT/Lincoln Labs lidar at JFK airport on May 31, 1997. The profiles range from 2.9 to 12.6 sec behind the MD11.

\section{SUMMARY AND CONCLUSIONS}

Figure 11 shows all the velocity core size estimates reported in this paper. In this figure, the triangles are the $\mathrm{C}-130$ data, the circles are the Idaho Falls B-757 measurements, the diamonds are the JFK B-757 measurements, and the squares are the JFK MD11 observations. The dashed line is a least squares fit to the data between $\mathrm{T}=0.5$ and 3.5. All the data presented is consistent in that the velocity core size is about 1 percent of wingspan and is nearly constant with distance behind the aircraft.

Comparing Figure 11 to Figure 5, we see that the smoke measurements show a vortex wake radius that is nearly twice as large as the velocity wake radius. As we stated earlier, we believe these larger smoke measurements are the result of the fact that the smoke is not located exclusively in the velocity core.

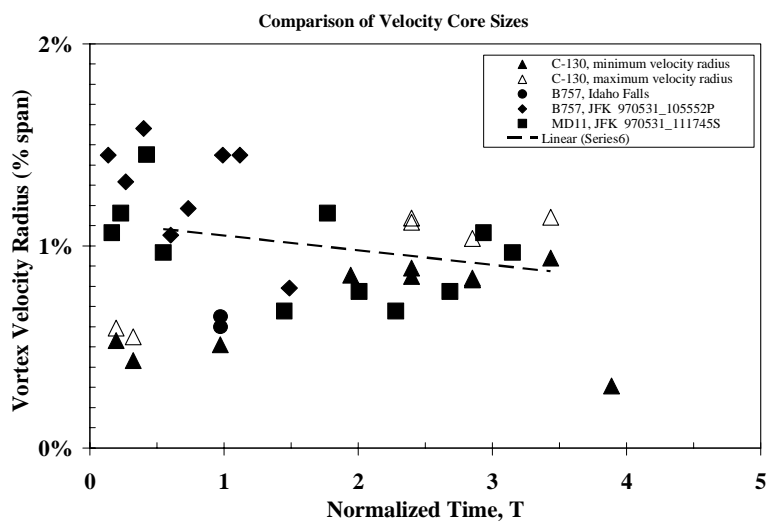

Figure 11. Summary plot of the velocity core size estimates reported in this paper. In this plot, the triangles are the $\mathrm{C}-130$ data, the circles are the Idaho Falls B-757 measurements, the diamonds are the JFK B-757 measurements, and the squares are the JFK MD11 observations. The dashed line is a least squares fit to the data between $T=0.5$ and 3.5 . From this plot, the velocity core size is about 1 percent of wingspan and is nearly constant with $T$.

The vortex cores shown in Figure 11 are significantly smaller than those used in current numerical models to study wake vortex evolution. Figure 12 shows velocity wake radii used in several recent numerical vortex studies, plotted vs. the year the study was reported. The dashed line represents the 1 percent velocity core size measurements shown in Figure 11.

Figure 12 shows that numerical models typically use vortex cores that are many times larger than aircraft cores. We hypothesize that, with larger core sizes than observed, the models will have difficulty simulating (a) realistic core instabilities, including linking into 3-D rings, (b) turbulence levels in the vortex cell (while maintaining tight cores), and (c) circulation decay, particularly in ground effect. All of these characteristics of vortex evolution play a role in 
predicting the hazard posed by and the lifetime of aircraft wake vortices.

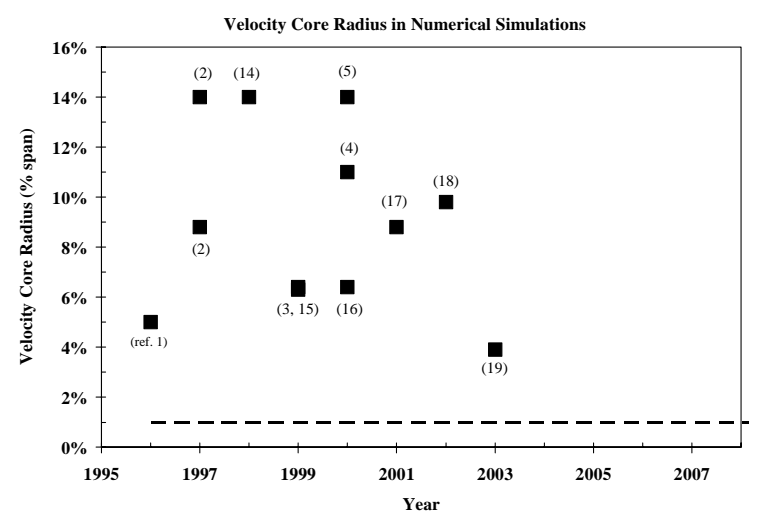

Figure 12. Velocity core radii used in recent numerical simulations. Reference numbers are in parentheses. The dashed line is the 1 percent result from Figure 11.

\section{ACKNOWLEDGMENTS}

We thank Bergen Delisi for performing the difficult and tedious job of processing the C-130 smoke data from videos. Useful discussions were held with David Burnham and Kirk Clawson on the Idaho Falls dataset. A significant portion of this work was performed under contract no. N00014-01-C-0367 with the U.S. Office of Naval Research. The support and encouragement of L. Patrick Purtell and Ronald D. Joslin are greatly appreciated.

\section{REFERENCES}

1 Proctor, F.H., 1996: Numerical Simulation of Wake Vortices Measured During the Idaho Falls and Memphis Field Programs, AIAA Paper 962496, 14th AIAA Applied Aerodynamic Conference, New Orleans.

2 Robins, R.E. and D.P. Delisi, 1997: Numerical Simulations of Three-Dimensional Trailing Vortex Evolution, AIAA Journal, 35, pp. 1552-1555.

3 Proctor, F.H. and J. Han, 1999: Numerical study of Wake Vortex Interaction with the Ground Using the Terminal Area Simulation System, AIAA Paper No. 99-0754, 37th Aerospace Sciences Meeting \& Exhibit, Reno.

4 Han, J., Y-L. Lin, S.P. Arya, and F.H. Proctor, 2000: Numerical Study of Wake Vortex Decay and
Descent in Homogeneous Atmospheric Turbulence, AIAA Journal, 38, pp. 643-656.

5 Delisi, D.P. and R.E. Robins, 2000: Short-Scale Instabilities in Trailing Wake Vortices in a Stratified Fluid, AIAA Journal, 38, pp. 1916-1923.

6 Vicroy, D.D., P.M. Vijgen, H.M. Reimer, J.L. Gallegos, and P.R. Spalart, 1998: Recent NASA Wake-Vortex Flight Tests, Flow-Physics Database and Wake-Development Analysis, Paper 985592, 1998 World Aviation Conference, Anaheim.

7 Burnham, D.C, and J.N. Hallock, 1982: Chicago Monostatic Acoustic Vortex Sensing System, Volume IV: Wake Vortex Decay, FAA-RD-79103, IV, Transportation Systems Center, Cambridge, MA, July.

8 Tombach, I., 1973: Observations of Atmospheric Effects on Vortex Wake Behavior, Journal of Aircraft, 10, pp.641-647.

9 Lissaman, P.B.S., S.C. Crow, P.B. MacCready Jr., I.H. Tombach, and E.R. Bate Jr., 1973: Aircraft Vortex Wake Descent and Decay under Real Atmospheric Effects, FAA-RD-73-120, AeroVironment Inc., Pasadena, CA, October.

10 Garodz, L.J. and K.L. Clawson, 1993: Vortex Wake Characteristics of B757-200 and B767-200 Aircraft Using the Tower Fly-By Technique, NOAA Technical Memorandum ERL ARL-199, January.

11 Robins, R.E., D.P. Delisi, and G.C. Greene, 2001: Algorithm for Prediction of Trailing Vortex Evolution, J. Aircraft, 38, pp. 911-917.

12 Heinrichs, R.M. and T. J. Dasey, 1997: Analysis of Circulation Data from a Wake Vortex Llidar, AIAA Paper No. 97-0059, 35th Aerospace Sciences Meeting \& Exhibition, Reno, NV.

13 Nguyen, D.P.C., 1998: Wake Vortex JFK2, RTI/4903-032-03S, Research Triangle Institute, prepared for NASA Langley Research Center, Hampton, VA, August.

14 Robins, R.E. and D.P. Delisi, 1998: Numerical Simulations of Three-Dimensional Trailing Vortex Evolution in Stratified Fluid, AIAA Journal, 36, 981-985.

15 Zheng, Z.C. and K. Baek, 1999: N-S Simulations of Crow-type Instabilities in Vortex Wake, AIAA 
Paper No. 99-0981, 37th Aerospace Sciences Meeting and Exhibition, Reno, NV.

16 Proctor, F.H., D.W. Hamilton, and J. Han, 2000: Wake Vortex Transport and Decay in Ground Effect: Vortex Linking with the Ground, AIAA Paper No. 2000-0757, 38th Aerospace Sciences Meeting and Exhibition, Reno, NV.

17 Garten, J.F., J. Werne, D.C. Fritts, and S. Arendt, 2001: Direct Simulations of the Crow Instability and Subsequent Vortex Reconnection in a Stratified Fluid, Journal of Fluid Mechanics, 426, pp. 1-45.
18 Rottman, J.W., D.G. Dommermuth, G.E. Innis, T.T. O'Shea, and E. Novikov, 2002: Numerical Simulation of Wakes in a Weakly Stratified Fluid, 24th Symposium on Naval Hydrodynamics, Fukuoka, Japan.

19 Robins, R.E. and D.P. Delisi, D.P., 2003: LES Simulation of High Reynolds Number Trailing Vortex Wakes, DoD HPCMP Users Group Meeting, Bellevue, WA. 